\title{
ПАТОПСИХОЛОГИЧЕСКАЯ СТРУКТУРА ВЛЕЧЕНИЯ К НАРКОТИКУ И КРИТИКА К БОЛЕЗНИ У ПАЦИЕНТОВ С ПОЛИНАРКОМАНИЯМИ
}

\section{PATHOPSYCHOLOGICAL STRUCTURE OF DRUG ATTRACTION AND CRITICISM TO DISEASE IN PATIENTS WITH POLYNARCOMMANIA}

M. Chaar

Summary: The article presents the results of a study of differences in awareness of the disease, as well as personality traits and emotional state in patients with varying degrees of severity of drug cravings. It has been established that the severity of affective and behavioral symptoms can lead awareness of patients in the disease. The study shows that with an average level of craving for drugs, patients have a formed awareness of their own state. This group of patients was characterized by a high level of self-control and anxiety, in comparison with the groups of patients with low and high levels of drug cravings. While, with a complete reduction of symptoms associated with low drug cravings, there is a decrease in criticism of their condition, which leads to the risk of relapse. Patients with a high level of craving for drugs have pronounced affective disorders, as well as sleep disturbances, as well as the readiness of patients for therapy, but the awareness of their illness is formal.

Keywords: addiction, addictive behavior, awareness of illness, anxiety.

\author{
Шаар Маалоули Мария \\ Аспирант, Российский государственный педагогический \\ университет им. А.И. Герцена (Санкт-Петербург) \\ mashashaarmaalouli@yandex.ru)
}

Аннотация: В статье представлены результаты исследования различий в критике к болезни, а также особенности личности и эмоционального состояния у пациентов с различной степенью тяжести влечения к наркотику. Установлено, что тяжесть аффективных и поведенческих симптомов может обуславливать критику пациентов в болезни. В работе показано, что при среднем уровне влечения к наркотику у пациентов наблюдается сформированная критика к собственному состоянию. Данная группа пациентов характеризовалась высоким уровнем самоконтроля и тревожности, в сравнении с группами пациентов с низким и высоким уровнем влечения к наркотику. В то время как, при полной редукции симптомов, связанных с влечением к наркотику, наблюдается снижение критики к своему состоянию, что обуславливает риск рецидива. У пациентов с высоким уровнем влечения к наркотику наблюдаются выраженные аффективные нарушения, а также нарушения сна, а также готовность пациентов к терапии, однако осознание своей болезни носит формальный характер.

Ключевые слова: степень влечения к наркотику, зависимое поведение, наркомания, критика к болезни.

ной степени определяет клинику и динамику заболевания. При рассмотрении феноменологии синдрома патологического влечения к наркотику многие исследователи имплицитно опираются на биологический подход, где центральным звеном являются нейрофизиологические механизмы, тормозящие иные побуждения пациентов с наркоманией. Подобный подход подразумевает единообразие симптомов и их прямую зависимость от длительности ремиссии. В то же самое время наблюдения за динамикой ремиссии показывает, что личностные и когнитивные особенности оценки собственного состояния оказывают значимое влияние на характер патологического влечения. Показано, что патологическое влечение в значительной степени влияет на длительность и качество ремиссий при заболеваниях зависимости. Эффективность реабилитационных мероприятий не превышает 15\% годовых ремиссий, что может быть связано с недостаточной разработанностью и научной обоснованностью проблемы изучения особенностей личности больных, а также оценкой тяжести влечения к наркотическим веществам [5]. 
Целью настоящего исследования являлось изучение патопсихологических и личностных особенностей пациентов с полинаркоманией с единообразной длительностью ремиссии в зависимости от тяжести влечения к наркотику.

\section{Материалы и методы исследования}

В исследовании принимали участие пациенты с полинаркоманией в возрасте 21- 47 лет. Общая выборка составила 33 человека, из них 23 мужчины и 10 женщин. Исследование проводилось с 18.02.2019 по 07.03.2020 года на базе Городской наркологической больницы, Межрегиональной благотворительной общественной организации «Благодать», и Городской психиатрической больницы № 3 имени И.И. Скворцова-Степанова в г. Санкт Петербург.

Для оценки патологического влечения и его основных патопсихологических симптомов, использовалась клиническая шкала оценка патологического влечения к наркотику Винниковой М.A $[2,3]$.

На основе суммарных оценок по данной шкале группа испытуемых была разделена на три группы: группа с низким уровнем влечением к наркотику $(\mathrm{M}=6, \mathrm{SD}=1.73)$ и составила 12 человек, группа со средним уровнем влечения к наркотику ( $M=13, S D=1.64)$ и составила 11 человек, группа с высоким уровнем влечения к наркотику ( $M=21$, $\mathrm{SD}=1.35)$ и составила 10 человек. Разделение на подгруппы осуществлялось с помощью метода k-средних. Bсе группы пациентов характеризовались примерно равным распределением по полу, а также длительности ремиссии (см.Таблица1).

Таблица 1.

Социально-демографические данные пациентов, страдающих наркотической зависимостью.

\begin{tabular}{|c|c|c|c|}
\hline $\begin{array}{c}\text { Уровень } \\
\text { влечения } \\
\text { наркотику }\end{array}$ & Возраст & $\begin{array}{c}\text { Соотношение } \\
\text { по полу }\end{array}$ & $\begin{array}{c}\text { Длительность } \\
\text { ремиссии } \\
\text { (в днях) }\end{array}$ \\
\hline $\begin{array}{c}\text { Низкий } \\
(n=12)\end{array}$ & $M=34,5, S D=4$ & $M=11, Ж=1$ & $M=36, S D=8$ \\
\hline $\begin{array}{c}\text { (редний } \\
\text { (n=11) }\end{array}$ & $M=35,5, S D=3,5$ & $M=11, Ж=0$ & $M=32, S D=6$ \\
\hline $\begin{array}{c}\text { Высокий } \\
(n=10)\end{array}$ & $M=36, S D=4$ & $M=9, Ж=1$ & $M=30, S D=9$ \\
\hline
\end{tabular}

Оценка личностных особенностей пациентов каждой из групп осуществлялась с помощью 16-ти факторного личностного опросника Р. Кеттела (форма С). Для оценки различий между тремя группами использовался непараметрический критерий Краскела-Уоллиса. Для представления значений центральных тенденций по шкале патологического влечения к наркотику М.А. Винниковой использовались значения моды (Мо). В качестве описательных статистик данных 16-ти факторного личностного опросника Р. Кеттела использовались значения медианы (Me).

\section{Результаты и их обсужАение}

В ходе проведённого исследования удалось выявить статистически значимые различия между групп пациентов с различной тяжестью зависимости. Группа пациентов с низким влечением к наркотику характеризуются

Таблица 2.

Результаты сравнения патопсихологической структуры влечения к наркотику у пациентов с различной тяжестью абстинентного синдрома (по данным клинической шкалы оценки патологического влечения к наркотику Винниковой М.А)

\begin{tabular}{|c|c|c|c|c|c|c|c|}
\hline & \multicolumn{2}{|c|}{$\begin{array}{c}\text { Группа } 1 \\
\text { (низкий } \\
\text { уровень) }\end{array}$} & \multicolumn{2}{|c|}{$\begin{array}{l}\text { Группа } 2 \\
\text { (средний } \\
\text { уровень) } \\
\end{array}$} & \multicolumn{2}{|c|}{$\begin{array}{l}\text { Группа } 3 \\
\text { (высокий } \\
\text { уровень) } \\
\end{array}$} & $\begin{array}{c}\text { Результаты } \\
\text { теста Краскела- } \\
\text { Уоллиса }\end{array}$ \\
\hline & Mo & $\%$ & Mo & $\%$ & Mo & $\%$ & $x 2, p$ \\
\hline Мысли о наркотике & 0 & 83 & 2 & 91 & 2 & 90 & $x 2=25.85, p=0.047^{*}$ \\
\hline Сниженное настроение & 1 & 83 & 2 & 91 & 3 & 90 & $x 2=26.30, p=0.039^{*}$ \\
\hline Тревога & 0 & 83 & 2 & 91 & 1 & 80 & $x 2=25.96, p=0.049^{*}$ \\
\hline Дисфория & 0 & 83 & 1 & 82 & 2 & 80 & $x 2=25.78, p=0.045^{*}$ \\
\hline Эмоциональная лабильность & 0 & 92 & 2 & 91 & 2 & 90 & $x 2=19.86, p=0.056$ \\
\hline Нарушения сна & 0 & 83 & 0 & 91 & 2 & 90 & $x 2=27.01, p=0.039 *$ \\
\hline $\begin{array}{l}\text { Поведенческие/ психопатоподобные } \\
\text { расстройства }\end{array}$ & 0 & 92 & 0 & 82 & 2 & 80 & $x 2=26.74, p=0.048^{*}$ \\
\hline Сновидения на наркотическую тематику & 0 & 92 & 2 & 91 & 3 & 90 & $x 2=26.25, p=0.038^{*}$ \\
\hline Установка на лечение & 1 & 92 & 1 & 91 & 2 & 90 & $x 2=18.96, p=0.061$ \\
\hline Критика к болезни & 2 & 92 & 1 & 91 & 2 & 90 & $x 2=19.36, p=0.057$ \\
\hline Общий уровень влечения к наркотику & \multicolumn{2}{|c|}{6} & \multicolumn{2}{|c|}{13} & \multicolumn{2}{|c|}{21} & $x 2=26.78, p=0.042^{*}$ \\
\hline
\end{tabular}

Примечание: Мо - мода, \% - процент наблюдений со значением моды, * - значимые различия 
аффективными нарушениями в виде снижения настроения (Mo=1, $\mathrm{p}=0.039)$, вялости и апатии. Присутствует положительная установка на лечение $(\mathrm{Mo}=1, \mathrm{p}=0.051)$ и частичная критика к собственному состоянию (Mo=2, $\mathrm{p}=0.053)$.

Группа со средним уровнем влечения к наркотику характеризуется аффективными нарушениями в виде снижения настроения (Mo=2, $\mathrm{p}=0.047)$, дисфорией $(\mathrm{Mo}=2$, $\mathrm{p}=0.045)$ и тревогой $(\mathrm{Mo}=2, \mathrm{p}=0.045)$, а также навязчивыми сновидениями, связанными с употреблением наркотика (Mo=1, $\mathrm{p}=0.038)$ и периодическими навязчивыми мыслями о наркотике в течение дня (Mo=2, $\mathrm{p}=0.047)$. У пациентов со средней степенью влечения к наркотику присутствует критика к своему состоянию (Мо=1, $\mathrm{p}=0.053)$, а также положительная установка на лечение (Mo=1, $\mathrm{p}=0.051)$.

Группа с высоким уровнем влечения к наркотику характеризуется навязчивыми мыслями о наркотике (Mo=3, p=0.047), которые слабо поддаются волевому контролю, а также регулярными сновидениями, связанными с наркотиком (Мо=3, p=0.038). Наблюдается обширный спектр эмоциональных и поведенческих нарушений, агрессивность (Mo=2, p=0.048), дисфория (Mo=2, $\mathrm{p}=0.045)$. Установка на лечение формальная $(\mathrm{Mo}=2$, $\mathrm{p}=0.051)$, критика к болезни частичная $(\mathrm{Mo}=2, \mathrm{p}=0.051)$.
Исследование личностных особенностей пациентов с различной силой влечения к наркотику показало, что группа с низким уровнем влечения к наркотику характеризуется общительностью, низкой эмоциональной стабильностью, экспрессивностью (см. Таблица 3). Данной группе также свойственна беззаботность и самонадеянность, экстраверсия и готовность идти на социальный контакт.

Группа пациентов со средним уровнем влечения к наркотику характеризуется замкнутостью, высоким уровнем тревожности, мнительности и чувством вины. Пациенты данной группы характеризуются более высоким уровнем самоконтроля в сравнении с другими двумя группами, а также сдержанностью в выражении эмоций, а также развитым самоконтролем. Группа пациентов с высоким уровнем влечения к наркотику характеризуется замкнутостью, эмоциональной неустойчивостью, низким самоконтролем. Данной группе пациентов свойственна готовность идти на неоправданный риск.

Полученные результаты, позволяют предположить, что тяжесть абстиненции и сила влечения к наркотику значимо связаны с патопсихологической структурой влечения к наркотику, а также личностными особенностями пациентов, страдающих наркотической зависимостью. Было установлено, что у пациентов со средним уров-

Таблица 3.

Описательные статистики и уровень значимости различий между тремя группами с различным уровнем тяжести влечения к наркотику

\begin{tabular}{|c|c|c|c|c|}
\hline \multirow{2}{*}{ Наименование шкалы } & Группа 1 & Группа 2 & Группа 3 & \multirow{2}{*}{$x 2, p$} \\
\hline & Me & Me & Me & \\
\hline замкнутость/общительность & 6.2 & 5.2 & 3.3 & $21.85,0.054^{*}$ \\
\hline развитое/ограниченное мышление & 3.2 & 4.3 & 3.2 & $10.27,0.156$ \\
\hline Независимость/податливость & 6.3 & 3.1 & 4.2 & $22.86,0.032^{*}$ \\
\hline эмоциональная стабильность/неустойчивость & 3,5 & 5 & 3 & $23.67,0.034^{*}$ \\
\hline \multicolumn{5}{|l|}{ сдержанность/ } \\
\hline экспрессивность & 6 & 3 & 4 & $18.23,0.75$ \\
\hline низкая/высокая нормотивность & 3 & 5 & 2 & $21.45,0.042^{*}$ \\
\hline робость/смелость & 7 & 4 & 7 & $23.34,0.051^{*}$ \\
\hline практицизм/чувствительность & 4 & 5 & 3 & $14.34,0.186$ \\
\hline практичность/мечтательность & 5 & 4 & 3 & $14.38,0.236$ \\
\hline прямоленейность/дипломатичность & 4 & 4 & 3 & $12.56,0.285$ \\
\hline спокойствие/тревожность & 3 & 8 & 3 & $27.56,0.023^{*}$ \\
\hline Радикализм/консерватизм & 4 & 3 & 5 & $17.48,0.067$ \\
\hline конформизм/нонконформизм & 3 & 5 & 3 & $26.68,0.041^{*}$ \\
\hline самоконтроль/недостаток самоконтроля & 3 & 6 & 2 & $24.54,0.041^{*}$ \\
\hline низкая тревожность/высокая тревожность & 3.5 & 8.4 & 4.6 & $25.56,0.044^{*}$ \\
\hline интроверсия/экстроверсия & 7.6 & 4.5 & 3.5 & $25.87,0.042^{*}$ \\
\hline чувствительность/уравновешенность & 5.2 & 4.7 & 3.2 & $14.34,0.117$ \\
\hline
\end{tabular}

Примечание: Ме-медианные значения, SD - стандартное отклонение, * - значимые различия 
нем влечения к наркотическим веществам наблюдается сохранная критика к своей болезни и положительная установка на лечение. При этом отмечается сохранность симптомов, связанных с влечением к наркотику, такими как сновидениями связанные с употреблением наркотика, а также периодическими навязчивыми о наркотике в течение дня. Так же отмечается высокий уровень самоконтроля, тревожности и мнительности, диагностированный как при помощи клинической шкалы М.А. Винниковой, так и при помощи многофакторного личностного опросника Р. Кеттела. Именно данные особенности личности и клинической картины могут лежать в основе критического отношения к болезни в данной группе пациентов. Так в качестве предиктора формирования осознания болезни может выступать личностная и ситуативная тревога, которая может стимулировать рефлексию пациентов в направлении анализа собственного состояния и возможных последствий наркозависимости. Полученные результаты также согласуются с данными, полученными Поляк О.Б., в работе которой отмечается, что осознание болезни у пациентов с опиодной зависимость связано с интернальным локусом контроля, самоконтролем и высоким уровнем тревожности [6,7].

Представляет интерес тот факт, формальное отношение к болезни наблюдается как в группе пациентов с низким уровнем влечения к наркотику, так и у пациентов с высоким уровнем. Данный факт может быть обусловлен тем, что редукции симптоматики может провоцировать у пациентов убеждение в ремиссии собственного состояния, при этом низкий уровень самоконтроля и эмоциональной стабильности может быть рассмотрен как предиктор возможных рецидивов. Современные исследования также показывают, что для наркозависимых с формальным отношением к болезни и анозогнозией характеризуются психологическими защитами по типу регрессии и отсутствием чувства вины в связи с употреблением наркотических веществ в прошлом $[1,7]$.

В группе пациентов с выраженным влечением к наркотику наблюдается готовность к лечению, что может быть обусловлено соматическими проявления абстинентного синдрома. При этом критика к собственному состоянию носит формальный характер. Наблюдаются выраженные нарушения аффективной сферы, такие как эмоциональна нестабильность, агрессивность.

\section{Выводы}

Таким образом, степень тяжести влечения к наркотику, а также патопсихологическая структура картины влечения к наркотику в значительной мере обуславливает критику пациента к болезни, а также готовность пациента к терапии. В нарушениях эмоциональной сферы у пациентов со средней степенью влечения к наркотику наблюдается сниженное настроение и высокий уровень тревоги, в то время как в группе с высоким уровнем влечения к наркотику в клинической картине эмоциональных нарушений преобладает дисфория и агрессия. Можно высказать предположение, что именно высокий уровень тревоги может обуславливать высокую критику к своему состоянию.

\section{Конфликт интересов отсутствует.}

\section{ЛИТЕРАТУРА}

1. Алехин, А.Н. Отношение к болезни у лиц с алкогольной зависимостью на разных этапах заболевания / А.Н. Алехин, А.В. Яровинская // Ученые записки университета им. П.Ф. Лесгафта. - 2011. - № 1 (71). - С. 7-13.

2. Винникова М.А. Ремиссии при героиновой наркомании (клиника, этапы течения, профилактика рецидивов): дис. д-ра мед. наук. - М., 2004. - 243 с.

3. Ненастьева А.Ю. Психометрические шкалы, использующиеся в клинической наркологии. // Наркология. Национальное руководство / под ред. Н.Н. Иванца, И.П. Анохиной, М.А. Винниковой. - 2-е изд., перераб. и доп. - М.: ГЭОТАР-Медиа, 2016. - С. 905-921

4. Пятницкая И.Н. Общая и частная наркология: руководство для врачей / И.Н. Пятницкая. — М.: ОАО «Издательство «Медицина», 2008. —640 с.

5. улаков С.А. Комплексная медицинская (психотерапевтическая) модель реабилитации пациентов с химическими и нехимическими формами аддикций, расстройствами личности, а также членов их семей / С.А. Кулаков, Ж.В. Береза, Е.К. Корчагина // Психическое здоровье. - 2014. - №1. - С.16-22.

6. Поляк О. Б. Механизмы психологической защиты наркозависимых и их взаимосвязь с особенностями личности // Известия РГПУ им. А.И. Герцена. 2008. №55. URL: https://cyberleninka.ru/article/n/mehanizmy-psihologicheskoy-zaschity-narkozavisimyh-i-ih-vzaimosvyaz-s-osobennostyami-lichnosti (дата обращения: 13.12.2020).

7. Поляк 0.Б. Личностные особенности наркозависимых с различным отношением к болезни // Известия РГПУ им. А.И. Герцена. 2009. №102. URL: https:// cyberleninka.ru/article/n/lichnostnye-osobennosti-narkozavisimyh-s-razlichnym-otnosheniem-k-bolezni (дата обращения: 13.12.2020).

(c) Шаар Маалоули Мария (mashashaarmaalouli@yandex.ru).

Журнал «Современная наука: актуальные проблемы теории и практики» 